PRIRODNE ZNANOSTI 



\title{
ODREĐIVANJE OPTIMALNIH STRATEGIJA ZA IGRANJE ŠIJAVICE POMOĆU TEORIJE IGARA
}

\begin{abstract}
SAŽETAK
Teorija igara je matematička disciplina koja modelirajući situacije iz stvarnog života kao igre te analizirajući konflikte koji se pojavljuju u tim igrama omogućava određivanje optimalnih strategija za postupanje u modeliranim situacijama. Teoriju igara moguće je primijeniti u raznovrsnim znanstvenim područjima, od matematike, preko ekonomije, do politike. $U$ radu su definirani osnovni pojmovi vezani uz teoriju igara i matrične igre, prikazano je modeliranje stare igre šijavica kao matrične igre te određene optimalne strategije za njeno igranje. Od 25 mogućih strategija za svakog igrača, samo je pet strategija koje treba odabirati i to tako da ih se odabire sjednakim vjerojatnostima. Također je provjereno da je igra poštena, tj. da su igrači ravnopravni u igri. Poznavanje optimalnih strategija za igranje neke igre igraču omogućuje da u igri postigne što bolji rezultat, sukladno zadanim pravilima igre, a neovisno o strategijama koje odabire protivnik.
\end{abstract}

Ključne riječi: teorija igara, matrična igra, matrica isplata, strategija, vrijednost igre

\section{UVOD}

Teorija igara je matematička disciplina koja se razvila polovinom 20. stoljeća. Njenim početkom smatra se knjiga Theory of Games and Economic Behavior (Teorija igara i ekonomsko ponašanje) koju su 1944. objavili matematičar John von Neumann i ekonomist Oskar Morgenstern. Teorija igara se otad počela naglo razvijati. Osim u matematici, primjenjuje se još i u ekonomiji, antropologiji, filozofiji, psihologiji, biologiji, politici, sportu...

Teorija igara temelji se na logičkoj analizi konfliktnih situacija, kao i situacija u kojima je moguća suradnja između dvaju ili više sudionika - igrača. Igra se definira kao situacija u kojoj:

1. sudjeluju barem dva igrača ( $s$ tim da igrač može biti jedna osoba, ali isto tako može biti i tim, tvrtka, narod ili čak i biološka vrsta);

2. svaki igrač ima određeni broj mogućih strategija, tj. akcija koje može odabrati;

3. svakom su mogućem ishodu igre pridružene isplate za svakog igrača koje predstavljaju vrijednost ishoda za različite igrače.

Teorija igara proučava kako bi igrači morali racionalno igrati igre. Svaki igračželi da igra završi tako da on dobije čim veću moguću isplatu. Igrač može donekle utjecati na iznos isplate, birajući strategiju, no isplata ne ovisi isključivo o njegovoj strategiji, već i o strategijama koje odabiru ostali igrači, pa

Mr. sc., predavač, Veleučilište u Rijeci, Vukovarska 58, 51000 Rijeka, Hrvatska. E-mail: kvolaric@veleri.hr

2 Datum primitka rada: 15. 1. 2017.; datum prihvaćanja rada: 15. 2. 2017. 
se tu pojavljuju konflikti i suradnja. Naime, ako više igrača uskladi svoje strategije, oni mogu postići da svi dobiju veće isplate. Racionalno igranje uključuje složene osobne odluke prilikom odabira strategije koja će igraču donijeti povoljan ishod, znajući da i svi ostali igrači biraju strategije tako da ishod bude povoljan za njih.

Cilj ovog istraživanja je odrediti optimalne strategije za igranje igre šijavica tako da se igra prikaže kao matrična igra te provjeriti je li igra poštena.

\section{MATRIČNE IGRE}

Najjednostavnija situacija je igra za dva igrača u kojoj svaki igrač može birati između dviju strategija, što znači da ukupno postoje četiri ishoda igre koje možemo prikazati tablicom. Primjer takve igre dan je u tablici 1.

Tablica 1. Ishodi igre

Drugi igrač

Prvi igrač

\begin{tabular}{|c|c|c|}
\hline & A & B \\
\hline A & $(3,-3)$ & $(-4,4)$ \\
\hline B & $(0,0)$ & $(6,-6)$ \\
\hline
\end{tabular}

Izvor: autorica

Prvi igrač bira jedan redak, dok drugi igrač istovremeno bira jedan stupac. Svaki igrač zapiše svoj izbor na papir. Igrači istovremeno otkrivaju svoj izbor i na temelju toga određuju isplate. Kod svakog je ishoda prvi član uređenog para isplata za prvog igrača, a drugi član isplata za drugog igrača.

U ovoj igri je zbroj isplata za svaki ishod jednak nuli. Drugim riječima, onoliko koliko prvi igrač dobije, toliko drugi izgubi, i obratno. Dakle, interesi igrača su izravno suprotni. Takva igra naziva se igra sa zbrojem nula i predstavlja situaciju čistog konflikta između dvoje igrača. Za takvu igru dovoljno je navesti isplate za prvog igrača za svaki ishod jer će isplata za drugog igrača kod svakog ishoda biti suprotan broj od isplate za prvog igrača za spomenuti ishod. Stoga igru možemo prikazati ovako:

Tablica 2. Tablica isplata

\begin{tabular}{c|c|c|c|}
\multicolumn{3}{c}{} & \multicolumn{3}{c|}{ Drugi igrač } \\
\cline { 2 - 4 } & & A & B \\
\cline { 2 - 4 } Prvi igrač & A & 3 & -4 \\
\hline B & 0 & 6 \\
\hline
\end{tabular}

Izvor: autorica 
Ovakvu tablicu u kojoj su navedeni iznosi koje drugi igrač isplaćuje prvom igraču jednostavnije prikazujemo matricom, u ovom primjeru $\left[\begin{array}{cc}3 & -4 \\ 0 & 6\end{array}\right]\left[\begin{array}{cc}3 & -4 \\ 0 & 6\end{array}\right]$, koju nazivamo matrica isplata, a igru određenu matricom isplata nazivamo matricna igra.

Prvi igrač želi odabrati redak tako da ishod bude čim veći, a drugi igrač želi odabrati stupac tako da ishod bude čim manji broj. U nastavku će biti uvedeni neki pojmovi teorije igara potrebni za razmatranje takve situacije.

Definicija 1. Strategija SS je dominantna nad strategijom TT ako je svaki ishod u $S S$ barem jednako dobar kao odgovarajući ishod u TT i barem jedan ishod u SS je strogo bolji od odgovarajućeg ishoda u TT.

Prema principu dominacije, racionalni igrač nikad neće odigrati strategiju koja nije dominantna. Taj princip može eliminirati strategije za koje postoji druga strategija koja je dominantna nad njima, tj. smanjiti mogućnost izbora za pojedinog igrača.

Definicija 2. Ishod matrične igre (s isplatama za igrača koji bira retke) naziva se sedlasta točka ako je isplata za taj ishod istovremeno manja ili jednaka svakoj isplati u tom retku i veća ili jednaka svakoj isplati u tom stupcu.

Definicija 3. Ako za matričnu igru postoji broj vv takav da prvi igrač ima strategiju koja mu jamči da će dobiti barem vv i drugi igrač ima strategiju koja mu jamči da prvi igrač neće dobiti više od $v v$, onda se $v v$ naziva vrijednost igre.

Ako je vrijednost igre jednaka nuli, igra je poštena, ako je vrijednost igre pozitivna, onda prvi igrač ima prednost, a ako je vrijednost igre negativna, onda drugi igrač ima prednost. Ako matrica isplata ima sedlastu točku, matrična igra je strogo određena, u njoj sreća ne igra ulogu, a vrijednost igre jednaka je isplati upisanoj na poziciji sedlaste točke.

Određivanje sedlaste točke provodi se tako da se ispišu minimumi svakog retka i među njima označi maksimum (maximin). Zatim se ispišu maksimumi svakog stupca i među njima označi minimum (minimax). Ako je maximin redaka jednak minimaxu stupaca, onda se on pojavljuje u sedlastoj točki. Jedna matrica isplata može imati više sedlastih točaka, ali su njihove vrijednosti tada jednake.

Ako matrična igra ima sedlastu točku, oba igrača će uvijek odabirati strategiju koja sadrži sedlastu točku. To se naziva čista strategija. U matričnim igrama koje nemaju sedlastu točku niti jedan igrač neće stalno odabirati istu strategiju kako to protivnik ne bi mogao iskoristiti, već će odabirati između nekoliko strategija. Mješovita strategija sastoji se od vjerojatnosti prema kojima prvi igrač bira retke, a drugi igrač bira stupce. Zbroj tih vjerojatnosti za pojedinog igrača iznosi 1. Budući da je svakom igraču u interesu da 
protivnik ne uoči pravilnost $u$ njegovom odabiru strategija, idealno je da igrač odabire strategiju na slučajan način, poštujući spomenute vjerojatnosti (npr. koristeći neki uređaj koji mu može pomoći u odluci koju strategiju da odabere).

Ako vjerojatnosti za prvog igrača zapišemo u retčanu matricu $P P$, a vjerojatnosti za drugog igrača zapišemo u stupčanu matricu $Q Q$ te označimo li matricu isplata s $A A$, umnožak $P \cdot A \cdot Q P \cdot A \cdot Q$ predstavlja očekivani dobitak prvog igrača.

Za navedeni primjer, ako drugi igrač igra mješovitu strategiju s vjerojatnostima $x x$ i $1-x$ $1-x$, izračunajmo očekivane vrijednosti za svaku strategiju prvog igrača:

$$
\left[\begin{array}{cc}
3 & -4 \\
0 & 6
\end{array}\right] \cdot\left[\begin{array}{c}
x \\
1-x
\end{array}\right]=\left[\begin{array}{c}
3 x-4+4 x \\
6-6 x
\end{array}\right]=\left[\begin{array}{c}
7 x-4 \\
6-6 x
\end{array}\right]
$$

Prvi igrač neće moći zloupotrijebiti mješovitu strategiju drugog igrača ako su ove dvije očekivane vrijednosti jednake:

$7 x-4=6-6 x$

$$
13 x=10
$$

$x=\frac{10}{13}$

$1-x=\frac{3}{13}$.

To znači da ako drugi igrač igra mješovitu strategiju $\left[\begin{array}{c}\frac{10}{13} \\ \frac{3}{13}\end{array}\right]\left[\begin{array}{c}\frac{10}{13} \\ \frac{3}{13}\end{array}\right]$, onda drugi igrač može biti siguran da prvi igrač prosječno neće dobiti više od $\frac{1818}{1313}$ jedinica po igri, neovisno o tome kako prvi igrač bude igrao.

Ako prvi igrač igra mješovitu strategiju s vjerojatnostima $y y$ i $1-y 1-y$, onda su očekivane vrijednosti za svaku strategiju drugog igrača:

$\left[\begin{array}{cc}y & 1-y\end{array}\right] \cdot\left[\begin{array}{cc}3 & -4 \\ 0 & 6\end{array}\right]=\left[\begin{array}{cc}3 y & -4 y+6-6 y\end{array}\right]=\left[\begin{array}{ll}3 y & -10 y+6\end{array}\right]$.

Drugi igrač neće moći zloupotrijebiti mješovitu strategiju prvog igrača ako su ove dvije očekivane vrijednosti jednake:

$3 y=-10 y+6$

$13 y=6$

$y=\frac{6}{13}$

$1-y=\frac{7}{13}$. 
Dakle, ako prvi igrač igra mješovitu strategiju $\left[\begin{array}{ll}\frac{6}{13} & \frac{7}{13}\end{array}\right]\left[\begin{array}{ll}\frac{6}{13} & \frac{7}{13}\end{array}\right]$, onda on može biti siguran da će prosječno dobiti barem $\frac{1818}{1313}$ jedinica po igri, neovisno o tome kako drugi igrač bude igrao.

U ovoj matričnoj igri je vrijednost igre $\frac{1818}{1313}$, optimalna strategija prvog igrača je $\left[\begin{array}{ll}\frac{6}{13} & \frac{7}{13}\end{array}\right]$

$\left[\begin{array}{ll}\frac{6}{13} & \frac{7}{13}\end{array}\right]$, a optimalna strategija drugog igrača $\left[\begin{array}{c}\frac{10}{13} \\ \frac{3}{13}\end{array}\right]\left[\begin{array}{c}\frac{10}{13} \\ \frac{3}{13}\end{array}\right]$. Vrijedi:

$\left[\begin{array}{cc}\frac{6}{13} & \frac{7}{13}\end{array}\right] \cdot\left[\begin{array}{cc}3 & -4 \\ 0 & 6\end{array}\right] \cdot\left[\begin{array}{c}\frac{10}{13} \\ \frac{3}{13}\end{array}\right]=\left[\frac{18}{13}\right]$

John von Neumann je 1928. dokazao sljedeći teorem:

Minimax teorem. Svaka matrična igra sa zbrojem nula za dva igrača ima rješenje. To znači da postoji jedinstveni broj $v v$ koji se naziva vrijednost igre i postoje optimalne (čiste ili mješovite) strategije za prvog i drugog igrača takve da:

1) ako prvi igrač igra svoju optimalnu strategiju, njegova očekivana isplata bit će $\geq v \geq v$, neovisno o ponašanju drugog igrača,

2) ako drugi igrač igra svoju optimalnu strategiju, očekivana isplata prvog igrača bit će $\leq v \leq v$, neovisno o ponašanju prvog igrača.

Zahvaljujući ovom teoremu pojmove optimalne strategije i vrijednosti igre možemo razmatrati za svaku matričnu igru, a ne samo za one koje su strogo određene. 


\section{3. ŠIJAVICA}

Šijavica (šije-šete, šijanje) je stara igra za dva igrača koja je rasprostranjena u Istri, Hrvatskom primorju i Dalmaciji. Igrači istovremeno pokazuju prste jedne ruke i pokušavaju pogoditi zbroj pokazanih prstiju tako da oba igrača istovremeno izvikuju broj koji može biti između 2 i 10. Brojevi se izvikuju na iskrivljenom talijanskom jeziku:

2 - do

3 - tre

4 - kvatro

5 - cinkve

6 - šije

7 - šete

8 - oto

9 - nove

10 - tuti (sve).

Igra je dobila naziv upravo po riječi "šije”, "šete” (sei, sette).

Ako niti jedan igrač ne pogodi zbroj pokazanih prstiju, ili ako oba igrača pogode, igrači ne dobivaju bodove. Ako samo jedan igrač pogodi zbroj pokazanih prstiju, taj igrač dobije jedan bod.

\section{ODREĐIVANJE RJEŠENJA IGRE ŠIJAVICA}

Šijavica je matrična igra za dva igrača sa zbrojem nula.

$\mathrm{Na}$ temelju pravila igre sastavimo matricu isplata. Koristimo oznaku "Piiljj" za "pokazuje $i i$, izvikuje $i j$ ". Uočimo da kad igrač pokaže $i i$ prstiju izvikuje jedan od brojeva $i+1 i+1$ $, i+2 i+2, i+3 i+3, i+4 i+4, i+5 i+5$ jer su to jedini zbrojevi koji se mogu postići zbrajanjem brojeva pokazanih prstiju oba igrača. 
Tablica 3. Matrica isplata za igru šijavica

\begin{tabular}{|c|c|c|c|c|c|c|c|c|c|c|c|c|c|c|c|c|c|c|c|c|c|c|c|c|c|}
\hline & P112 & \begin{tabular}{|l|l|l|} 
\\
\end{tabular} & P114 & P115 & P116 & $\mathrm{P} 213$ & P214 & P215 & \begin{tabular}{|l|} 
\\
\end{tabular} 216 & P217 & P314 & P315 & P316 & \begin{tabular}{|l|} 
\\
\end{tabular} 177 & P318 & P415 & $\mathrm{P} 416$ & P417 & P418 & P419 & P516 & P517 & P518 & P519 & P5110 \\
\hline $\begin{array}{l}\text { P1 } \\
12\end{array}$ & 0 & 1 & 1 & 1 & 1 & -1 & 0 & 0 & 0 & 0 & -1 & 0 & 0 & 0 & 0 & -1 & 0 & 0 & 0 & 0 & -1 & 0 & 0 & 0 & 0 \\
\hline $\begin{array}{l}\text { P1 } \\
\text { I3 }\end{array}$ & -1 & 0 & 0 & 0 & 0 & 0 & 1 & 1 & 1 & 1 & -1 & 0 & 0 & 0 & 0 & -1 & 0 & 0 & 0 & 0 & -1 & 0 & 0 & 0 & 0 \\
\hline $\begin{array}{l}\text { P1 } \\
14 \\
\end{array}$ & -1 & 0 & 0 & 0 & 0 & -1 & 0 & 0 & 0 & 0 & 0 & 1 & 1 & 1 & 1 & -1 & 0 & 0 & 0 & 0 & -1 & 0 & 0 & 0 & 0 \\
\hline $\begin{array}{l}\text { P1 } \\
15\end{array}$ & -1 & 0 & 0 & 0 & 0 & -1 & 0 & 0 & 0 & 0 & -1 & 0 & 0 & 0 & 0 & 0 & 1 & 1 & 1 & 1 & -1 & 0 & 0 & 0 & 0 \\
\hline $\begin{array}{l}\text { P1 } \\
16\end{array}$ & -1 & 0 & 0 & 0 & 0 & -1 & 0 & 0 & 0 & 0 & -1 & 0 & 0 & 0 & 0 & -1 & 0 & 0 & 0 & 0 & 0 & 1 & 1 & 1 & 1 \\
\hline $\begin{array}{l}\mathrm{P2} \\
13\end{array}$ & 1 & 0 & 1 & 1 & 1 & 0 & -1 & 0 & 0 & 0 & 0 & -1 & 0 & 0 & 0 & 0 & -1 & 0 & 0 & 0 & 0 & -1 & 0 & 0 & 0 \\
\hline $\begin{array}{l}2 \\
14\end{array}$ & 0 & -1 & 0 & 0 & 0 & 1 & 0 & 1 & 1 & 1 & 0 & -1 & 0 & 0 & 0 & 0 & -1 & 0 & 0 & 0 & 0 & -1 & 0 & 0 & 0 \\
\hline $\begin{array}{l}\mathrm{P2} \\
15\end{array}$ & 0 & -1 & 0 & 0 & 0 & 0 & -1 & 0 & 0 & 0 & 1 & 0 & 1 & 1 & 1 & 0 & -1 & 0 & 0 & 0 & 0 & -1 & 0 & 0 & 0 \\
\hline $\begin{array}{l}2 \\
16\end{array}$ & 0 & -1 & 0 & 0 & 0 & 0 & -1 & 0 & 0 & 0 & 0 & -1 & 0 & 0 & 0 & 1 & 0 & 1 & 1 & 1 & 0 & -1 & 0 & 0 & 0 \\
\hline $\begin{array}{l}\text { P2 } \\
17\end{array}$ & 0 & -1 & 0 & 0 & 0 & 0 & -1 & 0 & 0 & 0 & 0 & -1 & 0 & 0 & 0 & 0 & -1 & 0 & 0 & 0 & 1 & 0 & 1 & 1 & 1 \\
\hline $\begin{array}{l}\text { P3 } \\
14\end{array}$ & 1 & 1 & 0 & 1 & 1 & 0 & 0 & -1 & 0 & 0 & 0 & 0 & -1 & 0 & 0 & 0 & 0 & -1 & 0 & 0 & 0 & 0 & -1 & 0 & 0 \\
\hline $\begin{array}{l}\text { P3 } \\
15\end{array}$ & 0 & 0 & -1 & 0 & 0 & 1 & 1 & 0 & 1 & 1 & 0 & 0 & -1 & 0 & 0 & 0 & 0 & -1 & 0 & 0 & 0 & 0 & -1 & 0 & 0 \\
\hline $\begin{array}{l}33 \\
16\end{array}$ & 0 & 0 & -1 & 0 & 0 & 0 & 0 & -1 & 0 & 0 & 1 & 1 & 0 & 1 & 1 & 0 & 0 & -1 & 0 & 0 & 0 & 0 & -1 & 0 & 0 \\
\hline $\begin{array}{l}\text { P3 } \\
17\end{array}$ & 0 & 0 & -1 & 0 & 0 & 0 & 0 & -1 & 0 & 0 & 0 & 0 & -1 & 0 & 0 & 1 & 1 & 0 & 1 & 1 & 0 & 0 & -1 & 0 & 0 \\
\hline $\begin{array}{l}33 \\
18 \\
\end{array}$ & 0 & 0 & -1 & 0 & 0 & 0 & 0 & -1 & 0 & 0 & 0 & 0 & -1 & 0 & 0 & 0 & 0 & -1 & 0 & 0 & 1 & 1 & 0 & 1 & 1 \\
\hline $\begin{array}{l}\text { P4 } \\
15\end{array}$ & 1 & 1 & 1 & 0 & 1 & 0 & 0 & 0 & -1 & 0 & 0 & 0 & 0 & -1 & 0 & 0 & 0 & 0 & -1 & 0 & 0 & 0 & 0 & -1 & 0 \\
\hline $\begin{array}{l}\text { P4 } \\
16\end{array}$ & 0 & 0 & 0 & -1 & 0 & 1 & 1 & 1 & 0 & 1 & 0 & 0 & 0 & -1 & 0 & 0 & 0 & 0 & -1 & 0 & 0 & 0 & 0 & -1 & 0 \\
\hline $\begin{array}{l}\text { P4 } \\
17\end{array}$ & 0 & 0 & 0 & -1 & 0 & 0 & 0 & 0 & -1 & 0 & 1 & 1 & 1 & 0 & 1 & 0 & 0 & 0 & -1 & 0 & 0 & 0 & 0 & -1 & 0 \\
\hline $\begin{array}{l}\mathrm{P4} \\
18\end{array}$ & 0 & 0 & 0 & -1 & 0 & 0 & 0 & 0 & -1 & 0 & 0 & 0 & 0 & -1 & 0 & 1 & 1 & 1 & 0 & 1 & 0 & 0 & 0 & -1 & 0 \\
\hline $\begin{array}{l}4 \\
19 \\
\end{array}$ & 0 & 0 & 0 & -1 & 0 & 0 & 0 & 0 & -1 & 0 & 0 & 0 & 0 & -1 & 0 & 0 & 0 & 0 & -1 & 0 & 1 & 1 & 1 & 0 & 1 \\
\hline $\begin{array}{l}\text { P5 } \\
16\end{array}$ & 1 & 1 & 1 & 1 & 0 & 0 & 0 & 0 & 0 & -1 & 0 & 0 & 0 & 0 & -1 & 0 & 0 & 0 & 0 & -1 & 0 & 0 & 0 & 0 & -1 \\
\hline $\begin{array}{l}\text { P5 } \\
17 \\
\end{array}$ & 0 & 0 & 0 & 0 & -1 & 1 & 1 & 1 & 1 & 0 & 0 & 0 & 0 & 0 & -1 & 0 & 0 & 0 & 0 & -1 & 0 & 0 & 0 & 0 & -1 \\
\hline $\begin{array}{l}\mathrm{P5} \\
18\end{array}$ & 0 & 0 & 0 & 0 & -1 & 0 & 0 & 0 & 0 & -1 & 1 & 1 & 1 & 1 & 0 & 0 & 0 & 0 & 0 & -1 & 0 & 0 & 0 & 0 & -1 \\
\hline $\begin{array}{l}\text { P5 } \\
19\end{array}$ & 0 & 0 & 0 & 0 & -1 & 0 & 0 & 0 & 0 & -1 & 0 & 0 & 0 & 0 & -1 & 1 & 1 & 1 & 1 & 0 & 0 & 0 & 0 & 0 & -1 \\
\hline $\begin{array}{l}\text { P5 } \\
110 \\
\end{array}$ & 0 & 0 & 0 & 0 & -1 & 0 & 0 & 0 & 0 & -1 & 0 & 0 & 0 & 0 & -1 & 0 & 0 & 0 & 0 & -1 & 1 & 1 & 1 & 1 & \\
\hline
\end{tabular}

Izvor: autorica

Potražimo sedlastu točku. Budući da su minimumi svakog retka jednaki $-1-1$, a maksimumi svakog stupca jednaki 11, ova matrica isplata očito nema sedlastu točku. 
Potražimo dominantne strategije. Ne postoje dominantne strategije jer ne postoji neki redak u kojem bi svaki broj bio manji ili jednak odgovarajućem broju u nekom drugom retku. Analogna tvrdnja vrijedi i za stupce.

Odredimo optimalne strategije. lako smo kod matrične igre određene matricom isplata $2 \times 22 \times 2$ jednostavnim računanjem odredili optimalne strategije za svakog igrača, $u$ slučaju šijavice, čija je matrica isplata $25 \times 2525 \times 25$ to bi bilo vrlo zahtjevno, pa je za dobivanje rješenja korišten računalni program na mrežnoj stranici Calculating the Solution of a Matrix Game (https://www.math.ucla.edu/ tom/gamesolve.html).

Vrijednost igre je 0 , odnosno, igra je poštena. Optimalna strategija za prvog igrača je:

$$
(0,0,0,0,0.2,0.2,0,0,0,0,0,0,0.2,0,0,0,0.2,0,0,0,0,0,0,0.2,0) \text {. }
$$

Optimalna strategija za drugog igrača je:

$(0,0,0,0,0.2,0,0,0,0.2,0,0,0.2,0,0,0,0.2,0,0,0,0,0,0,0.2,0,0)$.

Ostaje nam još samo pronaći slučajni način odabira među pet optimalnih poteza za svakog igrača. Jedan od mogućih načina je da igrač na satu očita sekunde pa ako broj sekundi pri dijeljenju s pet daje ostatak jedan, odigra prvi potez, ako broj sekundi pri dijeljenju s pet daje ostatak dva, odigra drugi potez, ako broj sekundi pri dijeljenju s pet daje ostatak tri, odigra treći potez, ako broj sekundi pri dijeljenju s pet daje ostatak četiri, odigra četvrti potez, a ako je broj djeljiv s pet, odigra peti potez.

\section{ZAKLJUČAK}

U radu je prikazano određivanje optimalnih strategija za igranje igre šijavica koja je modelirana kao matrična igra za dva igrača sa zbrojem nula. Dobiven je rezultat da je za prvog igrača najbolje da s jednakom vjerojatnošću od $\frac{11}{55}$ igra strategije (poteze): P116, P213, P316, P416 i P519, dok je za drugog igrača najbolje da s jednakom vjerojatnošću od $\frac{11}{55}$ igra strategije (poteze): P116, P216, P315, P415 i P5I8. Također je izračunato da je vrijednost igre 00 , odnosno da je igra poštena.

\section{LITERATURA}

Calculating the Solution of a Matrix Game, https://www.math.ucla.edu/ tom/gamesolve.html (8. 1. 2017.)

Krčadinac, V. Teorija igara - matematičko modeliranje konfliktnih situacija, Hrvatski matematički elektronski časopis, broj 3, http://e.math.hr/old/teorijaigara/index.html (20. 12. 2016.)

Straffin, P. (1993) Game theory and strategy, vol. 36 Washington: The Mathematical Association of America Šijavica, https://hr.wikipedia.org/wiki/Šijavica (9. 1. 2017.) 


\title{
DETERMINING THE OPTIMAL STRATEGIES FOR PLAYING ŠIJAVICA BY USING GAME THEORY²
}

\begin{abstract}
Game theory is a mathematical discipline which by modeling real-life situations as games and analyzing the conflicts that occur in these games allows determining of optimal strategies for dealing with modeled situations. Game theory can be applied in various scientific fields, from mathematics, through the economy, to politics. The paper defines the basic concepts related to game theory and matrix games, showing the modeling of old game sijavica as a matrix game. Optimal strategies for playing the game are determined. Among the 25 possible strategies for each player, there are only five strategies to be chosen and they have to be chosen with equal probabilities. Also is verified that the game is fair, i.e. that the players are equal in the game. Knowing the optimal strategy for playing a game allows the player to achieve a better result, in accordance with established rules of the game, and regardless of the strategies chosen by the opponent.
\end{abstract}

Key words: game theory, matrix game, payoff matrix, strategy, value of the game

MSc, Lecturer, Polytechnic of Rijeka, Vukovarska 58, 51000 Rijeka, Croatia. E-mail: kvolaric@veleri.hr

2 Received: 15 January 2017; Accepted: 15 February 2017 
